\title{
A Cross-Sectional Study Demonstrating Increased Serum Amyloid A Related Inflammation in High-Density Lipoproteins from Subjects with Type 1 Diabetes Mellitus and How This Association Was Augmented by Poor Glycaemic Control
}

\author{
Jane McEneny, ${ }^{1}$ Jane-Ann Daniels, ${ }^{1}$ Anne McGowan, ${ }^{2}$ Anjuli Gunness, ${ }^{2}$ Kevin Moore, \\ Michael Stevenson, ${ }^{1}$ Ian S. Young, ${ }^{1}$ and James Gibney ${ }^{2}$ \\ ${ }^{1}$ Centre for Public Health, Queen's University Belfast, Institute of Pathology, Grosvenor Road, Belfast BT12 6BJ, UK \\ ${ }^{2}$ Department of Endocrinology, Tallaght Hospital, Dublin 24, Ireland
}

Correspondence should be addressed to Jane McEneny; j.mceneny@qub.ac.uk

Received 27 August 2014; Accepted 8 October 2014

Academic Editor: Gareth McKay

Copyright (C) 2015 Jane McEneny et al. This is an open access article distributed under the Creative Commons Attribution License, which permits unrestricted use, distribution, and reproduction in any medium, provided the original work is properly cited.

\begin{abstract}
Inflammatory atherosclerosis is increased in subjects with type 1 diabetes mellitus (T1DM). Normally high-density lipoproteins (HDL) protect against atherosclerosis; however, in the presence of serum amyloid-A- (SAA-) related inflammation this property may be reduced. Fasting blood was obtained from fifty subjects with T1DM, together with fifty age, gender and BMI matched control subjects. HDL was subfractionated into $\mathrm{HDL}_{2}$ and $\mathrm{HDL}_{3}$ by rapid ultracentrifugation. Serum-hsCRP and serum-, $\mathrm{HDL}_{2}-$, and $\mathrm{HDL}_{3}$-SAA were measured by ELISAs. Compared to control subjects, SAA was increased in T1DM subjects, nonsignificantly in serum $(P=0.088)$, and significantly in $\mathrm{HDL}_{2}(P=0.003)$ and $\mathrm{HDL}_{3}(P=0.005)$. When the T1DM group were separated according to mean $\mathrm{HbAlc}(8.34 \%)$, serum-SAA and $\mathrm{HDL}_{3}$-SAA levels were higher in the T1DM subjects with $\mathrm{HbAlc} \geq 8.34 \%$, compared to when HbAlc was $<8.34 \%(P<0.05)$. Furthermore, regression analysis illustrated, that for every $1 \%$-unit increase in HbAlc, SAA increased by $20 \%$ and $23 \%$ in $\mathrm{HDL}_{2}$ and $\mathrm{HDL}_{3}$, respectively, independent of BMI. HsCRP did not differ between groups $(P>0.05)$. This cross-sectional study demonstrated increased SAA-related inflammation in subjects with T1DM that was augmented by poor glycaemic control. We suggest that SAA is a useful inflammatory biomarker in T1DM, which may contribute to their increased atherosclerosis risk.
\end{abstract}

\section{Introduction}

Patients with type 1 diabetes mellitus (T1DM) have an elevated risk of coronary atherosclerosis and coronary heart disease (CHD) that is not explained by conventional risk factors [1]. In contrast to patients with type 2 diabetes mellitus (T2DM), their typical lipid profile is normal or even apparently better than the general population, with increased highdensity lipoprotein- (HDL-) cholesterol and decreased lowdensity lipoprotein- (LDL-) cholesterol and triglycerides [2]. However, these relatively simple lipid measurements potentially mask more subtle lipoprotein abnormalities, including disorders of lipoprotein function that might contribute to atherosclerosis in T1DM.
Serum amyloid-A (SAA) is an inflammatory protein that potentially contributes to dysfunctional HDL and progression of atherosclerosis. SAA has been detected in atherosclerotic lesions particularly in foam cells, is thought to be implicated in CHD [3] and may also indirectly cause plaque destabilization - an independent risk factor for cardiovascular disease (CVD) [4].

Studies investigating serum-SAA in subjects with T1DM have been inconclusive, some reporting increased levels [5] and others no difference [6]. However, to date, no studies have investigated if SAA is increased in HDL, specifically $\mathrm{HDL}_{2}$ and $\mathrm{HDL}_{3}$, in subjects with T1DM. There are several reasons for investigating SAA that is associated with HDL. Firstly, serum-SAA is reflective of both acute and chronic 
inflammation and, therefore, is influenced by short-term fluctuations in inflammation [7]. Secondly, SAA that is not associated with HDL is liable to proteolytic cleavage [8], which further influences its serum levels. Thirdly, as HDL has an approximate 4-day half-life in the circulation [9], SAA associated with this lipoprotein is more stable and thus more reflective of chronic low-grade inflammation. Finally and most importantly, because HDL function is impaired by SAA within the particle rather than in serum [10-12], direct measurement of HDL-associated SAA is necessary to demonstrate that it may be of pathological significance in T1DM.

Therefore, investigation of SAA in HDL subfractions in T1DM enhances our knowledge of its usefulness as a marker of inflammation and may also provide evidence of a mechanistic link between inflammation and atherosclerosis/CVD in these patients. To assess this, SAA was measured in serum, $\mathrm{HDL}_{2}$, and $\mathrm{HDL}_{3}$ in patients with T1DM and compared to well-matched control group. Further analysis was carried out to determine the contribution of glycaemic control on these variables.

\section{Materials and Methods}

2.1. Study Population. Patients with T1DM $(n=50)$ were recruited from the Diabetes Database in Tallaght Hospital, Dublin, Ireland, and were not reported to have preexisting CVD. Subjects without diabetes were recruited by local advertisement or were relatives of the TIDM patients. The inclusion criteria for subjects in the T1DM group were as follows: T1DM, between 20 and 45 years of age, and BMI less than $30 \mathrm{~kg} / \mathrm{m}^{2}$, while the inclusion criteria for the control group were as follows: nondiabetic, between 20 and 45 years of age, and BMI less than $30 \mathrm{~kg} / \mathrm{m}^{2}$. All subjects gave their written signed consent to the study, which was approved by the Research Ethics Committee of the Adelaide and Meath Hospital and St. James' Hospital (Dublin, Ireland).

2.2. Blood Processing. Blood was collected into standard serum tubes by the vacuette system and was allowed to sit at room temperature for a period of $30 \mathrm{mins}$ to allow clotting. Serum was obtained by centrifugation at $3000 \mathrm{rpm}$ for $15 \mathrm{mins}$ at $4^{\circ} \mathrm{C}$. The serum supernatant was removed and frozen in $1.3 \mathrm{~mL}$ aliquots in a $-80^{\circ} \mathrm{C}$ freezer, until required for further analysis.

2.3. Primary Laboratory Analysis. Baseline measurements included fasting serum levels of glucose, total cholesterol, triglycerides, HDL cholesterol, and LDL cholesterol, which were measured using standard enzymatic assays on an automated ILab-600 biochemical analyser (Cobas Roche Diagnostics, West Sussex, UK). HbAlc was measured in serum by ion exchange HPLC and high-sensitivity C-reactive protein (hsCRP) was measured by an enzyme linked immunosorbent assay (ELISA) using a commercial available kit (BioCheck Inc., Foster City, USA). Height $(\mathrm{cm})$ and weight $(\mathrm{kg})$ were collected using a stadiometer and calibrated scales and used to determine BMI $\left(\mathrm{kg} / \mathrm{m}^{2}\right)$. These primary laboratory analyses were carried out in the laboratories of Tallaght Hospital, Dublin.

2.4. Isolation of $H D L_{2}$ and $H D L_{3}$ from Serum. $\mathrm{HDL}_{2}$ and $\mathrm{HDL}_{3}$ were harvested from freshly thawed serum by rapid ultracentrifugation, according to the method of McPherson et al. [13]. This is a 3-step, 6-hour long procedure.

2.5. Protein and Apo AI Determination. The protein concentration of $\mathrm{HDL}_{2}$ and $\mathrm{HDL}_{3}$ was determined spectrophotometrically using a commercial version of the Bradford assay (Bio-Rad, Hemel Hempstead, UK), as previously described [13]. Total protein concentration was utilised to standardise SAA within $\mathrm{HDL}_{2}$ and $\mathrm{HDL}_{3}$. Apo AI concentration was determined by single radial immunodiffusion, as previously described [13].

2.6. SAA Concentration in Serum, $H D L_{2}$, and $H D L_{3}$. SAA was measured in serum, $\mathrm{HDL}_{2}$ and $\mathrm{HDL}_{3}$ by a commercially available ELISA procedure (Invitrogen, KHA0011), which detects human-SAA1 and SAA2. The analysis was performed on a Grifols TRITURUS ELISA system (Italy), as per the manufacturer's instructions, with the following modifications. Serum was diluted $1: 150, \mathrm{HDL}_{2} 1: 10$ and $\mathrm{HDL}_{3} 1: 100$. The intra- and interassay precision of this assay were both $<8 \%$. This kit did not cross-react with a wide range of other proteins, including CRP, TNF- $\alpha$, and IL- 6 .

2.7. Statistical Analysis. Statistical analyses were performed using SPSS (Statistical Package for the Social Sciences) Statistics version 21. Variables were assessed for normality and logarithmically transformed where required. Between-group analyses were analysed by independent $t$-test for normal $(n=49)$ versus TIDM subjects $(n=50)$ (described as comparison 1), and between T1DM subjects when separated according to HbAlc; that is, the T1DM group was separated into two groups according to mean $\mathrm{HbAlc}(<8.34 \%$ $(68 \mathrm{mmol} / \mathrm{mol}) n=24$ or $\geq 8.34 \%(68 \mathrm{mmol} / \mathrm{mol}) n=26)$. This secondary analysis is described as comparison 2 . The relationship between $\mathrm{HbAlc}$ and SAA was further assessed by linear regression. Correlations were determined by Pearson's coefficient. All variables were summarised as mean (standard deviation, SD) when normally distributed and as geometric mean (interquartile range) when normally distributed after logarithmic transformation. Significance was set as $P \leq 0.05$.

\section{Results}

3.1. Subject Characteristics. Subjects with hsCRP $>10 \mathrm{mg} / \mathrm{L}$ were removed from the analyses ( $n=1$ in control group) as this is suggestive of an active infection/inflammation and is in accordance with American Heart Association Guidelines [14].

Subject characteristics are shown in Table 1. These illustrate that when control subjects were compared to overall T1DM subjects (comparison 1), BMI, age, gender, totalcholesterol, and HDL-cholesterol were comparable between 
the groups $(P>0.05$ for all analyses), while triglycerides and LDL-cholesterol were lower in T1DM $(P \leq 0.05$ for both analyses). As was to be expected, fasting plasma glucose and HbAlc were higher in T1DM subjects $(P \leq 0.001$ for both analyses). There were a small number of subjects in the T1DM group who were receiving statin therapy $(5 / 50)$, while none of the control subjects were receiving lipid lowering therapy.

To explore the effect of glycaemic control in T1DM, we performed a further analysis where the T1DM group was subdivided into patients with HbAlc $<(n=24)$ or $\geq(n=26)$ the median value $(8.34 \% ; 68 \mathrm{mmol} / \mathrm{mol})$. The results for this analysis are presented as comparison 2 in Table 1 , where BMI, age, gender, fasting glucose, triglycerides, HDL-cholesterol, and LDL-cholesterol were similar between the two T1DM groups $(P>0.05$ for all analyses). However, total cholesterol was lower in the T1DM group with $<8.34 \% \mathrm{HbAlC}(P<$ $0.05)$. As anticipated HbAlc was lower in the T1DM subjects in the group with $\mathrm{HbAlc}<8.34 \%$, compared to the TiDM subjects with $\mathrm{HbAlc} \geq 8.34 \%(P \leq 0.001)$.

3.2. Total Protein and Apo AI Concentration in $H D L_{2}$ and $H L_{3}$. The results illustrated that compared to control subjects, total protein was significantly higher in $\mathrm{HDL}_{2}(242$ (90) versus $277(86) \mathrm{mg} / \mathrm{L} ; P=0.047)$ and significantly lower in $\mathrm{HDL}_{3}$ (2720 (793) versus 2410 (614) $\mathrm{mg} / \mathrm{L} ; P=$ 0.033 ) in the overall T1DM group (comparison 1). Analysis in comparison 2 demonstrated that the difference in $\mathrm{HDL}_{2}$ protein resulted from higher levels in the T1DM group with HbAlc $\geq 8.34 \%$, compared to T1DM group with HbAlc < $8.34 \%$ (295 (92) versus 259 (76) $\mathrm{mg} / \mathrm{L} ; P<0.05$ ), while the difference in $\mathrm{HDL}_{3}$ protein resulted from lower protein levels in T1DM group with HbAlc $<8.34 \%$, compared to the T1DM group with $\mathrm{HbAlc} \geq 8.34 \%$ (2271 (588) versus 2538 (620) $\mathrm{mg} / \mathrm{L} ; P<0.05)$. $\mathrm{HDL}_{2}$ and $\mathrm{HDL}_{3}$ apo AI concentration were comparable between the control and TIDM groups in comparison $1\left(\mathrm{HDL}_{2}, 162(86)\right.$ versus $146(51) \mathrm{mg} / \mathrm{L} ; P=$ 0.255: $\mathrm{HDL}_{3}, 1590$ (690) versus 1583 (344) $\mathrm{mg} / \mathrm{L} ; P=0.951$ ). There was also no difference in $\mathrm{HDL}_{2}$ and $\mathrm{HDL}_{3}$ apo $\mathrm{AI}$ in the

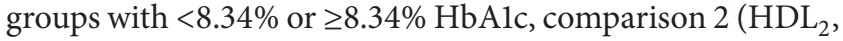
141 (56) versus 150 (48) $\mathrm{mg} / \mathrm{L} ; P=0.508: \mathrm{HDL}_{3}, 1575$ (356) versus $1591(338) \mathrm{mg} / \mathrm{L} ; P=0.869)$.

\section{3. hsCRP in Serum and SAA in Serum, $H D L_{2}$, and $H D L_{3}$}

Serum Analyses. Serum-hsCRP did not differ between the groups in comparison 1 or $2(P=0.162$ and $P=0.355$, resp., Table 2). Although serum-SAA appeared higher in the overall T1DM group from comparison 1 , this only approached significance compared to the control group $(P=0.088)$. However, in comparison 2, serum-SAA was statistically higher in the T1DM group with HbAlc $\geq 8.34 \%$, compared to the T1DM group HbAlc $<8.34 \%(P=0.031)$.

HDL Analyses. Compared to the control group, the protein standardised and nonstandardised SAA in $\mathrm{HDL}_{2}$ and $\mathrm{HDL}_{3}$ was statistically higher in the overall T1DM group from comparison 1 ( $P<0.05$, for both analyses). Comparison 2 illustrated that protein and nonprotein standardised $\mathrm{HDL}_{2}-$ SAA, although appeared higher in the T1DM group with HbAlc $\geq 8.34 \%$, it was not statistically different compared to the T1DM group with HbAlc $<8.34 \%(P=0.096$ and 0.085 , resp.). However, both protein and nonprotein standardised $\mathrm{HDL}_{3}$-SAA was statistically higher in the T1DM group with HbAlc $\geq 8.34 \%$, compared to the T1DM group with HbAlc $<$ $8.34 \%(P=0.028$ and 0.019 , resp. $)$.

3.4. Relationship between HbAlc and SAA. The relationship between $\mathrm{HbAlc}$ and SAA was further examined by linear regression analysis. This revealed a positive relationship between increased $\mathrm{HbAlc}$ and both $\mathrm{HDL}_{2}$-SAA and $\mathrm{HDL}_{3}$ SAA (Figures 1(a) and 1(b), resp.; $P<0.001$ for both analyses), where every $1 \%$ unit increase in HbAlc was associated with an estimated 20\% (CI; 8-33\%) increase in $\mathrm{HDL}_{2}$-SAA and an estimated $23 \%$ (CI; $10-37 \%$ ) increase in $\mathrm{HDL}_{3}$-SAA. This relationship was further examined when we excluded the control group from this analysis. Here the positive relationship continued, although this was only significant for $\mathrm{HDL}_{3}\left(\mathrm{HDL}_{2} ; r=0.306, P=0.098: \mathrm{HDL}_{3}\right.$; $r=0.452, P=0.027)$. No relationship was found between HbAlc and serum-SAA $(r=0.187 ; P=0.110)$. BMI, age, and gender did not impact on our model, meaning that they were not included in our regression analyses.

3.5. Correlations between SAA and hsCRP with Subject Characteristics. There was a strong positive correlation between serum-SAA and SAA associated with $\mathrm{HDL}_{2}$ and $\mathrm{HDL}_{3}(P \leq$ 0.001 for both correlations, Table 3 ). In addition, the presence of T1DM was positively correlated with serum-SAA, $\mathrm{HDL}_{2}-$ $\mathrm{SAA}$, and $\mathrm{HDL}_{3}-\mathrm{SAA}$, although this was only significant for the HDL subfractions ( $P=0.093,0.014$ and 0.011 , resp.). BMI was positively correlated with serum-SAA and $\mathrm{HDL}_{3}$-SAA ( $P=0.002$ for both correlations). Fasting plasma glucose, age, and gender were not correlated with serum-SAA, $\mathrm{HDL}_{2}-$ SAA, or $\mathrm{HDL}_{3}$-SAA $(P>0.05$ for all correlations). hsCRP was moderately correlated with serum-SAA $(P=0.038$, Table 3$)$ and negatively correlated with age $(P=0.007)$. HsCRP did not correlate with the presence of T1DM, glucose, BMI, or gender $(P>0.05$ for all correlations, Table 3$)$ or with $\operatorname{HbAlc}(r=0.212 ; P=0.075)$.

\section{Discussion}

This is the first reported study to examine SAA in HDL in subjects with T1DM, illustrating that SAA was increased in the main subtypes of $\mathrm{HDL}, \mathrm{HDL}_{2}$, and $\mathrm{HDL}_{3}$. The antiatherogenic properties of HDL particles include their pivotal role in reverse cholesterol transport [15], as well as antioxidant [16] and anti-inflammatory effects [17]. However, in the presence of SAA-related inflammation, these antiatherogenic properties are impaired [18-20]. Following release into the circulation, SAA associates with $\mathrm{HDL}$, particularly $\mathrm{HDL}_{3}$ [21], which can augment atherogenesis, as SAA enhances the binding of HDL to the arterial wall [22]. Furthermore, dysfunctional HDL displays reduced reverse cholesterol transport and antioxidant capabilities [23]. In the current 
TABLE 1: Subject characteristics for comparison 1 and comparison 2.

\begin{tabular}{|c|c|c|c|c|c|c|}
\hline \multirow[b]{2}{*}{ Characteristic } & \multicolumn{3}{|c|}{ Comparison 1} & \multicolumn{3}{|c|}{ Comparison 2} \\
\hline & $\begin{array}{l}\text { Control group } \\
\quad(n=49)\end{array}$ & $\begin{array}{l}\text { T1DM group } \\
\quad(n=50)\end{array}$ & $t$-test & $\begin{array}{l}\text { T1DM group } \\
\text { HbAlc }<8.34 \% \\
(n=24)\end{array}$ & $\begin{array}{l}\text { T1DM group } \\
\text { HbAlc } \geq 8.34 \% \\
(n=26)\end{array}$ & $t$-test \\
\hline BMI $\left(\mathrm{kg} / \mathrm{m}^{2}\right)$ & $26.4(3.5)$ & $26.0(3.9)$ & 0.686 & $25.0(3.5)$ & $27.0(4.1)$ & 0.062 \\
\hline Age (years) & $39.4(10.1)$ & $35.8(8.3)$ & 0.095 & $36.8(9.1)$ & $35.0(7.5)$ & 0.451 \\
\hline Gender (male : female) & $17: 32$ & $18: 32$ & 0.836 & $9: 15$ & $9: 17$ & 0.836 \\
\hline Fasting glucose $(\mathrm{mmol} / \mathrm{L})$ & $5.05(4.60,5.30)$ & $9.89(6.30,14.60)$ & $\leq 0.001$ & $9.05(5.20,12.80)$ & $10.63(6.58,14.85)$ & 0.279 \\
\hline $\operatorname{HbAlC~(\% )}$ & $5.3(5.1,5.5)$ & $8.3(7.4,8.8)$ & $\leq 0.001$ & $7.4(6.8,8.0)$ & $9.2(8.6,9.7)$ & $\leq 0.001$ \\
\hline $\mathrm{HbAlc}(\mathrm{mmol} / \mathrm{mol})$ & $34(32,37)$ & $68(57,72)$ & $\leq 0.001$ & $57(51,64)$ & $76(70,83)$ & $\leq 0.001$ \\
\hline Total cholesterol $(\mathrm{mmol} / \mathrm{L})$ & $4.92(0.86)$ & $4.60(0.84)$ & 0.065 & $4.36(0.83)$ & $4.83(0.80)$ & 0.048 \\
\hline Triglycerides $(\mathrm{mmol} / \mathrm{L})$ & $1.31(0.77)$ & $1.04(0.39)$ & 0.050 & $0.98(0.34)$ & $1.09(0.44)$ & 0.330 \\
\hline HDL cholesterol $(\mathrm{mmol} / \mathrm{L})$ & $1.41(0.34)$ & $1.50(0.41)$ & 0.204 & $1.43(0.52)$ & $1.57(0.28)$ & 0.231 \\
\hline LDL cholesterol (mmol/L) & $2.99(0.84)$ & $2.62(0.68)$ & 0.032 & $2.48(0.57)$ & $2.75(0.76)$ & 0.157 \\
\hline Statin therapy (number) & 0 & 5 & NA & 1 & 4 & NA \\
\hline ACE Inhibitors (number) & 0 & 5 & $\mathrm{NA}$ & 2 & 3 & NA \\
\hline
\end{tabular}

Results expressed as mean (SD) or when data was not normally distributed as geometric mean (interquartile range).

TABLE 2: Serum hsCRP and Serum, $\mathrm{HDL}_{2}$ and $\mathrm{HDL}_{3}$ SAA concentration.

\begin{tabular}{|c|c|c|c|c|c|c|}
\hline \multirow[b]{2}{*}{ Analyate } & \multicolumn{3}{|c|}{ Comparison 1} & \multicolumn{3}{|c|}{ Comparison 2} \\
\hline & $\begin{array}{l}\text { Control group } \\
\quad(n=49)\end{array}$ & $\begin{array}{l}\text { T1DM group } \\
(n=50)\end{array}$ & $t$-test & $\begin{array}{l}\text { T1DM group } \\
\text { HbAlc }<8.34 \% \\
(n=24)\end{array}$ & $\begin{array}{l}\text { T1DM group } \\
\text { HbAlc } \geq 8.34 \% \\
(n=26)\end{array}$ & $t$-test \\
\hline Serum-hsCRP (mg/L) & $1.97(1.00,2.38)$ & $2.89(1.00,4.40)$ & 0.162 & $2.56(1.00,2.30)$ & $3.24(1.30,4.93)$ & 0.355 \\
\hline Serum-SAA $(\mu \mathrm{g} / \mathrm{L})$ & $16241(7275,17645)$ & $23837(8133,40737)$ & 0.088 & $15885(8060,18945)$ & $\begin{array}{c}30706(7984 \\
47986)\end{array}$ & 0.031 \\
\hline \multicolumn{7}{|l|}{ Protein-standardised SAA } \\
\hline $\mathrm{HDL}_{2}(\mu \mathrm{g} / \mathrm{mg}$ protein$)$ & $3.00(0.97,4.12)$ & $5.63(1.65,7.63)$ & 0.003 & $4.97(1.41,4.42)$ & $6.23(2.06,9.94)$ & 0.096 \\
\hline $\mathrm{HDL}_{3}(\mu \mathrm{g} / \mathrm{mg}$ protein $)$ & $3.48(1.37,3.55)$ & $5.95(2.31,9.57)$ & 0.005 & $4.50(1.18,5.01)$ & $7.34(2.35,12.29)$ & 0.028 \\
\hline \multicolumn{7}{|c|}{ Nonprotein standardised SAA } \\
\hline $\mathrm{HDL}_{2}(\mu \mathrm{g} / \mathrm{L})$ & $690(242,951)$ & $1674(379,1990)$ & 0.004 & $1260(357,1408)$ & $2055(541,2589)$ & 0.085 \\
\hline $\mathrm{HDL}_{3}(\mu \mathrm{g} / \mathrm{L})$ & $8951(3326,8966)$ & $15972(4625,23331)$ & 0.005 & $10362(3883,13315)$ & $21151(6846,33534)$ & 0.019 \\
\hline
\end{tabular}

Results expressed as mean (SD) or when data was not normally distributed as geometric mean (interquartile range).

study, SAA was increased by $53 \%$ in $\mathrm{HDL}_{2}$ and $58 \%$ in $\mathrm{HDL}_{3}$ in subjects with T1DM. This SAA had been standardised to total protein, which was $15 \%$ higher in $\mathrm{HDL}_{2}$ and $14 \%$ lower in $\mathrm{HDL}_{3}$, compared to the control subjects. These differences were small compared to differences in SAA and, therefore, were unlikely to have significantly influenced the HDL-SAA results. However, to ensure this was not the case we also included the nonprotein standardised SAA results, where the difference in HDL-SAA between the groups was maintained.

To examine the relationship between glycaemic control and HDL-SAA levels, we separated the overall T1DM group according to mean $\mathrm{HbAlc}(<$ or $\geq 8.34 \%$ ), where the differences identified in comparison 1 was, in the main, driven by higher HDL-SAA levels in the T1DM subjects with poor glycaemic control (HbAlc $\geq 8.34 \%$; comparison 2 ). Although prolonged poor glycaemic control is associated with chronic inflammation [24], the mechanisms underlying the association between increased SAA and T1DM are not clear. However, there is evidence that SAA promotes insulin resistance [25] and that intensive insulin therapy can reduce SAA levels [4], whilst the insulin-sensitising and antioxidant drug troglitazone is reported to lower SAA in T2DM subjects [26]. In support of the concept that glycaemic control and inflammation are linked, the current study further illustrated that glycaemic control was closely associated with increased SAA-related inflammation, where for every $1 \%$ unit increase in $\mathrm{HbAlc}$ there was a concomitant increase in $\mathrm{HDL}_{2}$ and $\mathrm{HDL}_{3}$-associated SAA of $20 \%$ and $23 \%$, respectively. However, and contrary to this, Heliövaara et al. [6] reported that serum-SAA did not respond to glycaemic intervention to lower HbAlc in T1DM subjects, although we suggest that this may not have been the case had they measured HDL-SAA. Additionally, this group [6] only reported a $0.8 \%$ decrease in $\mathrm{HbAlc}$ following intervention, which may have been insufficient to mediate a statistical effect. Finally, their small subject population (24 subjects with T1DM) may 


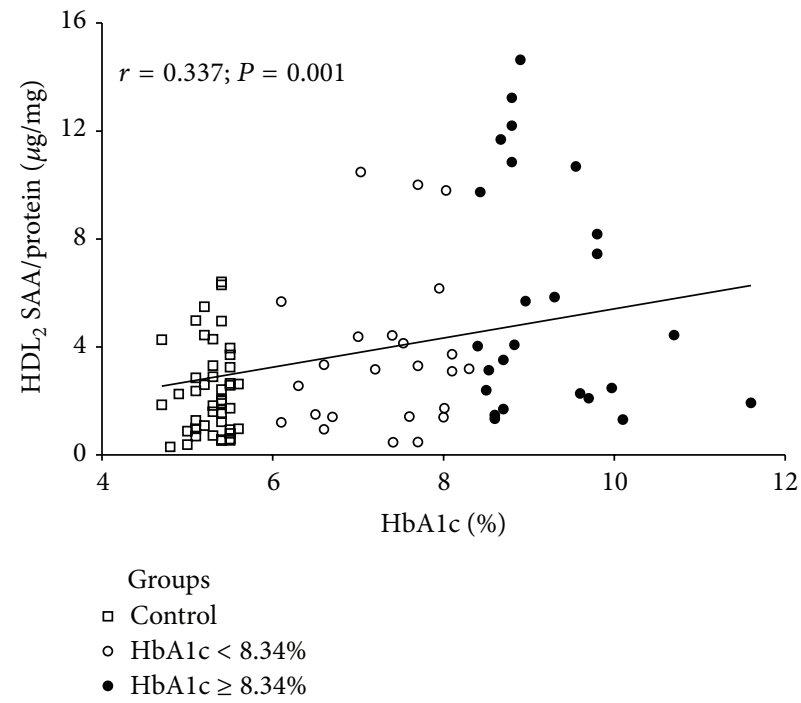

(a)

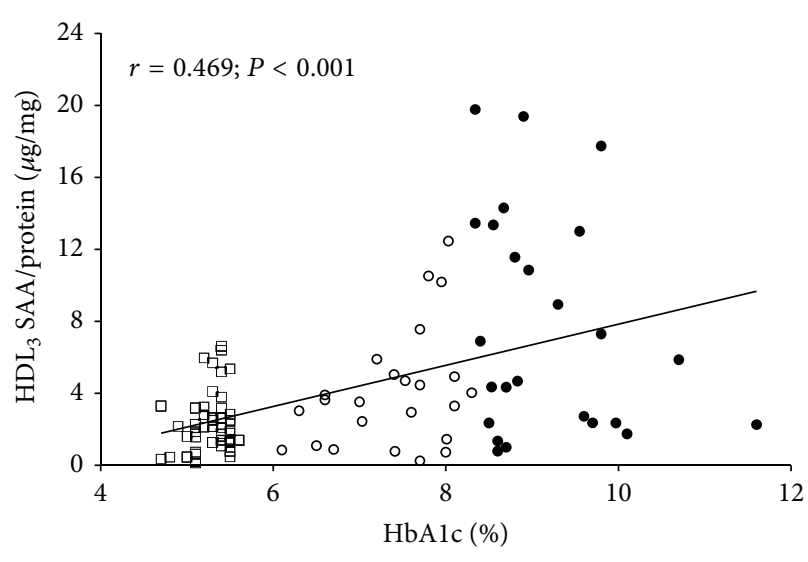

Groups

- Control

- $\mathrm{HbA} 1 \mathrm{c}<8.34 \%$

- $\mathrm{HbAlc} \geq 8.34 \%$

FIgURE 1: Relationship between $\mathrm{HbAl}_{\mathrm{c}}$ and SAA in $\mathrm{HDL}_{2}$ (a) and $\mathrm{HDL}_{3}$ (b).

TABLE 3: Correlations between SAA and subject characteristics.

\begin{tabular}{|c|c|c|c|c|}
\hline & $\begin{array}{c}\text { Serum-SAA } \\
r=; P=\end{array}$ & $\begin{array}{c}\mathrm{HDL}_{2} \text {-SAA } \\
r=; P=\end{array}$ & $\begin{array}{c}\mathrm{HDL}_{3}-\mathrm{SAA} \\
r=; P=\end{array}$ & $\begin{array}{l}\text { hsCRP } \\
r=; P=\end{array}$ \\
\hline Serum-SAA & - & $0.779 ; \leq 0.001$ & $0.888 ; \leq 0.001$ & $0.234 ; 0.038$ \\
\hline T1DM status & $0.191 ; 0.093$ & $0.246 ; 0.014$ & $0.256 ; 0.011$ & $0.206 ; 0.062$ \\
\hline BMI & $0.349 ; 0.002$ & $0.044 ; 0.663$ & $0.302 ; 0.002$ & $0.196 ; 0.076$ \\
\hline Fasting plasma glucose & $0.063 ; 0.730$ & $0.134 ; 0.457$ & $0.113 ; 0.539$ & $-0.124 ; 0.267$ \\
\hline Age & $0.070 ; 0.541$ & $-0.056 ; 0.585$ & $-0.011 ; 0.917$ & $-0.294 ; 0.007$ \\
\hline Gender & $0.197 ; 0.082$ & $0.139 ; 0.169$ & $0.155 ; 0.129$ & $0.077 ; 0.491$ \\
\hline
\end{tabular}

T1DM status: control $=0$; type $1=1$.

have minimised their power to detect a change in serumSAA, especially as serum-SAA is reported to display a large standard deviation (as discussed in detail below).

Overall, and to the author's knowledge, this is the first study to demonstrate an association between glycaemic control and levels of HDL-SAA in subjects with T1DM, and we suggest that a possible mechanism may be a result of an "underinsulinised" liver in poorly controlled T1DM subjects.

With regard to our serum-SAA results, although serumSAA was higher in the poorly controlled T1DM subjects (HbA1c $\geq 8.34 \%)$ in comparison $2(P=0.031)$, betweengroup differences were less clear-cut between the overall T1DM subjects and the control subjects from comparison $1(P=0.088)$. We can suggest several reasons for this anomaly; firstly, the T1DM subjects with better glycaemic control (HbAlc < 8.34\%; comparison 2) may have impacted on the T1DM result in comparison 1 . Secondly, as serum-SAA displays a large variation, as illustrated by our wide spread of interquartile ranges reported in Table 2, this would minimise our statistical power. In fact, a large standard deviation was suggested to be responsible for the nonsignificantly higher levels of serum-SAA reported in 24 T1DM subjects, compared to 16 control subjects [6]. Further credence to this concept may be provided by Zhi et al. [5], where they reported statistically higher serum-SAA levels in a very large T1DM cohort (1139 T1DM subjects versus 848 control subjects). Furthermore, although Basu et al. [27] reported that serumSAA was not different in a T1DM/control group comparison with similar subject numbers to our current study (38 T1DM subjects versus 41 control subjects), we suggest that this may be due to their control group being under greater inflammatory stress, as both serum-SAA and hsCRP were higher in their control group.

Overall, we suggest that the apparently lower sensitivity of serum-SAA, compared to the HDL subfractions, possibly reflects differences between acute and chronic inflammation. As described under Introduction, serum-SAA is indicative of both acute and chronic inflammation [7] and, therefore, more subject to daily fluctuations, which may impact greatly when subject numbers are small. In contrast, since HDL has a half-life of approximately 4 days [9], SAA associated with this lipoprotein is predicted to be more stable and, therefore, a more useful marker of chronic low grade inflammation in both small and large cohorts. 


\section{Conclusions}

In summary, this cross-sectional study has highlighted HDLSAA as a sensitive biomarker to detect increased inflammation in subjects with T1DM and provides a potential mechanistic explanation for accelerated atherosclerosis of this condition. Longitudinal studies are required to explore whether SAA changes in response to improved glycaemic control in T1DM.

Study Limitations. There are several limitations to this study. Firstly, we must address the fact that several of our T1DM patients were on statin therapy (10\%), which is known to lower SAA levels, especially under conditions of heightened inflammation [28]. However, this was also the group in which SAA was increased, suggesting that SAA may have been even higher had none of the TIDM subjects been on this therapy. Secondly, several of our T1DM subjects were taking ACE inhibitors, which are reported to increase SAA [29]. However, although this may appear, in part, to have driven the difference between the T1DM and control cohorts, this could not be the case as ACE inhibitor use was similar in the two T1DM cohorts, while SAA levels were different. This would suggest that it was unlikely that the ACE inhibitors had influenced SAA levels in this study. Thirdly, our lack of an ability to detect statistically significant differences in serumSAA between our overall T1DM group and the control group may be due to our relatively small subject numbers and the fact that SAA is known to display a large variation between subjects. Fourthly, we did not examine SAA associated with VLDL and LDL, which has recently been shown to be increased in subjects with documented atherosclerosis [30]. Fifthly, due to our small subject numbers meant that it was not possible to correlate SAA with established CVD risk factors, such as intimal media thickness. Sixthly, we also acknowledge that it is desirable for HbAlc to be $\leq 7 \%$ to reduce the vascular complications of diabetes and to indicate a better-controlled T1DM cohort [31]. However, in the current study only 5 of our 50 T1DM patients had an HbAlc of $\leq 7 \%$, meaning that it was not possible to carry out such a sub analysis. Finally, we must address the differing HDL-protein concentrations identified between the control and T1DM groups, which we suggest may be related to changes in HDL-associated proteins, relative to T1DM status. In the case of $\mathrm{HDL}_{2}$, this may be related, in part, to the increased SAA protein identified in the T1DM subjects, and, in the case of $\mathrm{HDL}_{3}$, this may be related to changes in the concentration of other HDLassociated proteins, such as paraoxonase-1, which readily associates with $\mathrm{HDL}_{3}[32]$ and is influenced by inflammation [33].
Abbreviations
CVD: Cardiovascular disease
HbAlc: Glycated haemoglobin
HDL: High-density lipoprotein
hsCRP: High-sensitivity C-reactive protein
SAA: Serum amyloid A
T1DM: Type 1 diabetes mellitus.

\section{Conflict of Interests}

None of the authors had any conflict of interests.

\section{Authors' Contribution}

Jane McEneny devised this project. Jane McEneny and Ian Young supervised Jane-Ann Daniels who undertook the work. Anne McGowan and Anjuli Gunness were responsible for subject recruitment. Kevin Moore and James Gibney supervised Anne McGown and Anjuli Gunness. Michael Stevenson did the statistical analyses. Jane McEneny and James Gibney prepared the manuscript for publication and Jane McEneny had the final say in its submission.

\section{References}

[1] S. D. de Ferranti, I. H. de Boer, and V. Fonseca, "Type 1 diabetes mellitus and cardiovascular disease. A scientific statement from the American Heart Association and American Diabetes Association," Circulation, vol. 130, pp. 1110-1130, 2014.

[2] J. Guy, L. Ogden, R. P. Wadwa et al., "Lipid and lipoprotein profiles in youth with and without type 1 diabetes: the SEARCH for diabetes in youth case-control study," Diabetes Care, vol. 32, no. 3, pp. 416-420, 2009.

[3] R. L. Meek, S. Urieli-Shoval, and E. P. Benditt, "Expression of apolipoprotein serum amyloid A mRNA in human atherosclerotic lesions and cultured vascular cells: implications for serum amyloid A function," Proceedings of the National Academy of Sciences of the United States of America, vol. 91, no. 8, pp. 31863190, 1994.

[4] J.-L. Du, J.-F. Liu, L.-L. Men et al., "Effects of five-year intensive multifactorial intervention on the serum amyloid $\mathrm{A}$ and macroangiopathy in patients with short-duration type 2 diabetes mellitus," Chinese Medical Journal, vol. 122, no. 21, pp. 2560-2566, 2009.

[5] W. Zhi, A. Sharma, S. Purohit et al., "Discovery and validation of serum protein changes in type 1 diabetes patients using high throughput two dimensional liquid chromatographymass spectrometry and immunoassays," Molecular \& Cellular Proteomics, vol. 10, pp. 1-10, 2011.

[6] M. K. Heliövaara, A.-M. Teppo, S.-L. Karonen, J. A. Tuominen, and P. Ebeling, "Improved glycaemia in type 1 diabetes results in decreased levels of soluble adhesion molecules with no change in serum adiponectin or most acute phase proteins," Experimental and Clinical Endocrinology and Diabetes, vol. 114, no. 6, pp. 295-300, 2006.

[7] T. Chiba, C. Y. Han, T. Valsar et al., "Serum amyloid A3 does not contribute to circulating SAA levels," Journal of Lipid Research, vol. 50, no. 7, pp. 1353-1362, 2009.

[8] L. L. Bausserman and P. N. Herbert, "Degradation of serum amyloid A and apolipoproteins by serum proteases," Biochemistry, vol. 23, no. 10, pp. 2241-2245, 1984.

[9] A. Scanu and W. L. Hughes, "Further characterization of the human serum D 1.063-1.21, $\alpha_{1}$-lipoprotein," The Journal of Clinical Investigation, vol. 41, no. 8, pp. 1681-1689, 1962.

[10] A. Artl, G. Marsche, S. Lestavel, W. Sattler, and E. Malle, "Role of serum amyloid A during metabolism of acute-phase HDL by macrophages," Arteriosclerosis, Thrombosis, and Vascular Biology, vol. 20, no. 3, pp. 763-772, 2000. 
[11] J. B. Ancsin and R. Kisilevsky, "Serum amyloid A peptide interactions with glycosaminoglycans. Evaluation by affinity chromatography," Methods in Molecular Biology, vol. 171, pp. 449-456, 2001.

[12] V. L. King, J. Thompson, and L. R. Tannock, "Serum amyloid A in atherosclerosis," Current Opinion in Lipidology, vol. 22, no. 4, pp. 302-307, 2011.

[13] P. A. McPherson, I. S. Young, B. McKibben, and J. McEneny, "High density lipoprotein subfractions: isolation, composition, and their duplicitous role in oxidation," The Journal of Lipid Research, vol. 48, no. 1, pp. 86-95, 2007.

[14] T. A. Pearson, G. A. Mensah, R. W. Alexander et al., "Markers of inflammation and cardiovascular disease: application to clinical and public health practice: a statement for healthcare professionals from the centers for disease control and prevention and the American Heart Association," Circulation, vol. 107, no. 3, pp. 499-511, 2003.

[15] J. A. Farmer and J. Liao, "Evolving concepts of the role of highdensity lipoprotein in protection from atherosclerosis," Current Atherosclerosis Reports, vol. 13, no. 2, pp. 107-114, 2011.

[16] D. Hine, B. MacKness, and M. MacKness, "Coincubation of PON1, APO A1, and LCAT increases the time HDL is able to prevent LDL oxidation," IUBMB Life, vol. 64, no. 2, pp. 157-161, 2012.

[17] S. Loued, M. Isabelle, H. Berrougui, and A. Khalil, "The antiinflammatory effect of paraoxonase 1 against oxidized lipids depends on its association with high density lipoproteins," Life Sciences, vol. 90, no. 1-2, pp. 82-88, 2012.

[18] B. Mackness, P. N. Durrington, and M. I. Mackness, "Human serum paraoxonase," General Pharmacology, vol. 31, no. 3, pp. 329-336, 1998.

[19] P. M. M. Weers, A. B. Patel, L. C.-P. Wan et al., "Novel Nterminal mutation of human apolipoprotein A-I reduces selfassociation and impairs LCAT activation," Journal of Lipid Research, vol. 52, no. 1, pp. 35-44, 2011.

[20] X. Qiu, A. Mistry, M. J. Ammirati et al., "Crystal structure of cholesteryl ester transfer protein reveals a long tunnel and four bound lipid molecules," Nature Structural and Molecular Biology, vol. 14, no. 2, pp. 106-113, 2007.

[21] N. Eriksen and E. P. Benditt, "Isolation and characterization of the amyloid-related apoprotein (SAA) from human high density lipoprotein," Proceedings of the National Academy of Sciences of the United States of America, vol. 77, no. $11 \mathrm{I}, \mathrm{pp} .6860-$ $6864,1980$.

[22] T. Chiba, M. Y. Chang, S. Wang et al., "Serum amyloid a facilitates the binding of high-density lipoprotein from mice injected with lipopolysaccharide to vascular proteoglycans," Arteriosclerosis, Thrombosis, and Vascular Biology, vol. 31, no. 6, pp. 1326-1332, 2011.

[23] A. Kontush and M. J. Chapman, "Functionally defective highdensity lipoprotein: a new therapeutic target at the crossroads of dyslipidemia, inflammation, and atherosclerosis," Pharmacological Reviews, vol. 58, no. 3, pp. 342-374, 2006.

[24] A. Festa, R. D’Agostino Jr., G. Howard, L. Mykkänen, R. P. Tracy, and S. M. Haffner, "Chronic subclinical inflammation as part of the insulin resistance syndrome: the insulin resistance atherosclerosis study (IRAS)," Circulation, vol. 102, no. 1, pp. 4247, 2000.

[25] F. B. Filippin-Monteiro, E. M. de Oliveira, S. Sandri, F. H. Knebel, R. C. Albuquerque, and A. Campa, "Serum amyloid A is a growth factor for 3T3-L1 adipocytes, inhibits differentiation and promotes insulin resistance," International Journal of Obesity, vol. 36, no. 8, pp. 1032-1039, 2012.

[26] P. Ebeling, A.-M. Teppo, H. A. Koistinen et al., "Troglitazone reduces hyperglycaemia and selectively acute-phase serum proteins in patients with Type II diabetes," Diabetologia, vol. 42, no. 12, pp. 1433-1438, 1999.

[27] S. Basu, A. Larsson, J. Vessby, B. Vessby, and C. Berne, "Type 1 diabetes is associated with increased cyclooxygenase- and cytokine-mediated inflammation," Diabetes Care, vol. 28, no. 6, pp. 1371-1375, 2005.

[28] S. Kinlay, G. G. Schwartz, A. G. Olsson et al., "High-dose atorvastatin enhances the decline in inflammatory markers in patients with acute coronary syndromes in the MIRACL study," Circulation, vol. 108, no. 13, pp. 1560-1566, 2003.

[29] T. Yoshida, A. M. Tabony, S. Galvez et al., "Molecular mechanisms and signaling pathways of angiotensin II-induced muscle wasting: potential therapeutic targets for cardiac cachexia," International Journal of Biochemistry and Cell Biology, vol. 45, no. 10, pp. 2322-2332, 2013.

[30] A. J. Lepedda, G. Nieddu, E. Zinellu et al., "Proteomic analysis of plasma-purified VLDL, LDL, and HDL fractions from atherosclerotic patients undergoing carotid endarterectomy: identification of serum amyloid a as a potential marker," Oxidative Medicine and Cellular Longevity, vol. 2013, Article ID 385214, 11 pages, 2013.

[31] E. S. Kilpatrick, A. S. Rigby, and S. L. Atkin, "Variability in the relationship between mean plasma glucose and $\mathrm{HbA}_{1 c}$ : implications for the assessment of glycemic control," Clinical Chemistry, vol. 53, no. 5, pp. 897-901, 2007.

[32] P. Davidsson, J. Hulthe, B. Fagerberg, and G. Camejo, "Proteomics of apolipoproteins and associated proteins from plasma high-density lipoproteins," Arteriosclerosis, Thrombosis, and Vascular Biology, vol. 30, no. 2, pp. 156-163, 2010.

[33] C. Y. Han, T. Chiba, J. S. Campbell et al., "Reciprocal and coordinate regulation of serum amyloid A versus apolipoprotein AI and paraoxonase-1 by inflammation in murine hepatocytes," Arteriosclerosis, Thrombosis, and Vascular Biology, vol. 26, no. 8, pp. 1806-1813, 2006. 


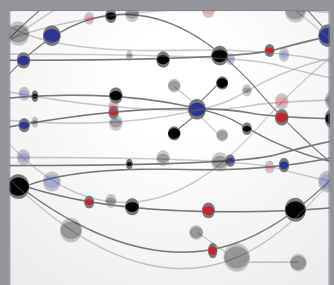

The Scientific World Journal
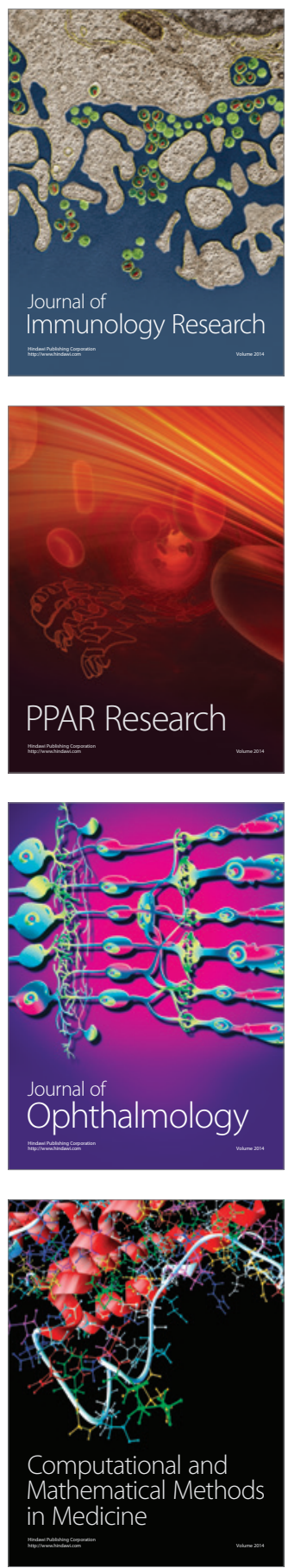

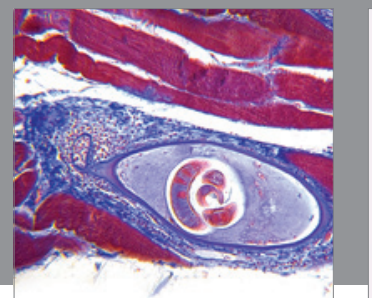

Gastroenterology

Research and Practice
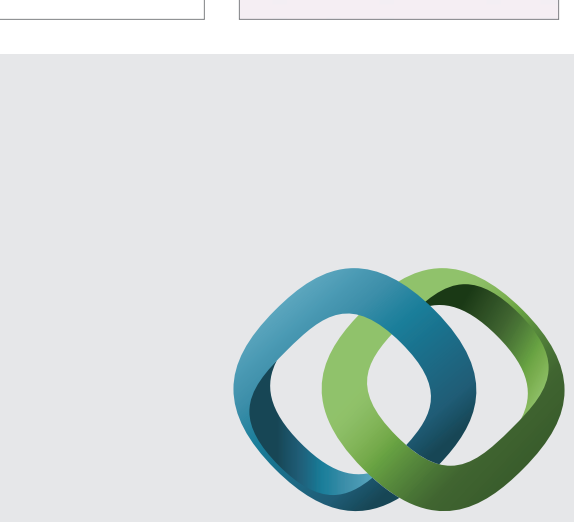

\section{Hindawi}

Submit your manuscripts at

http://www.hindawi.com
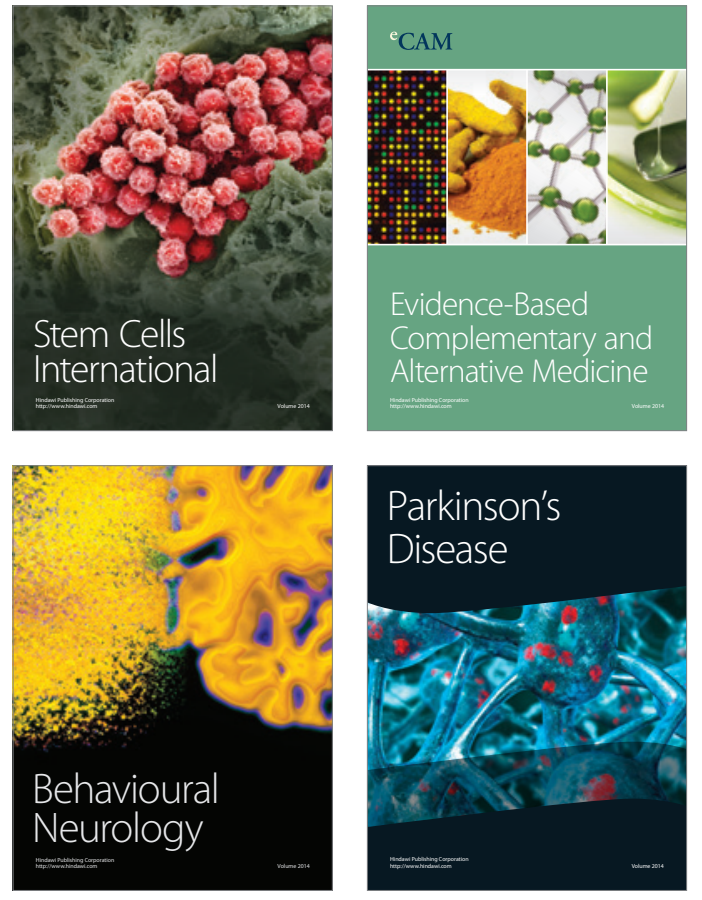
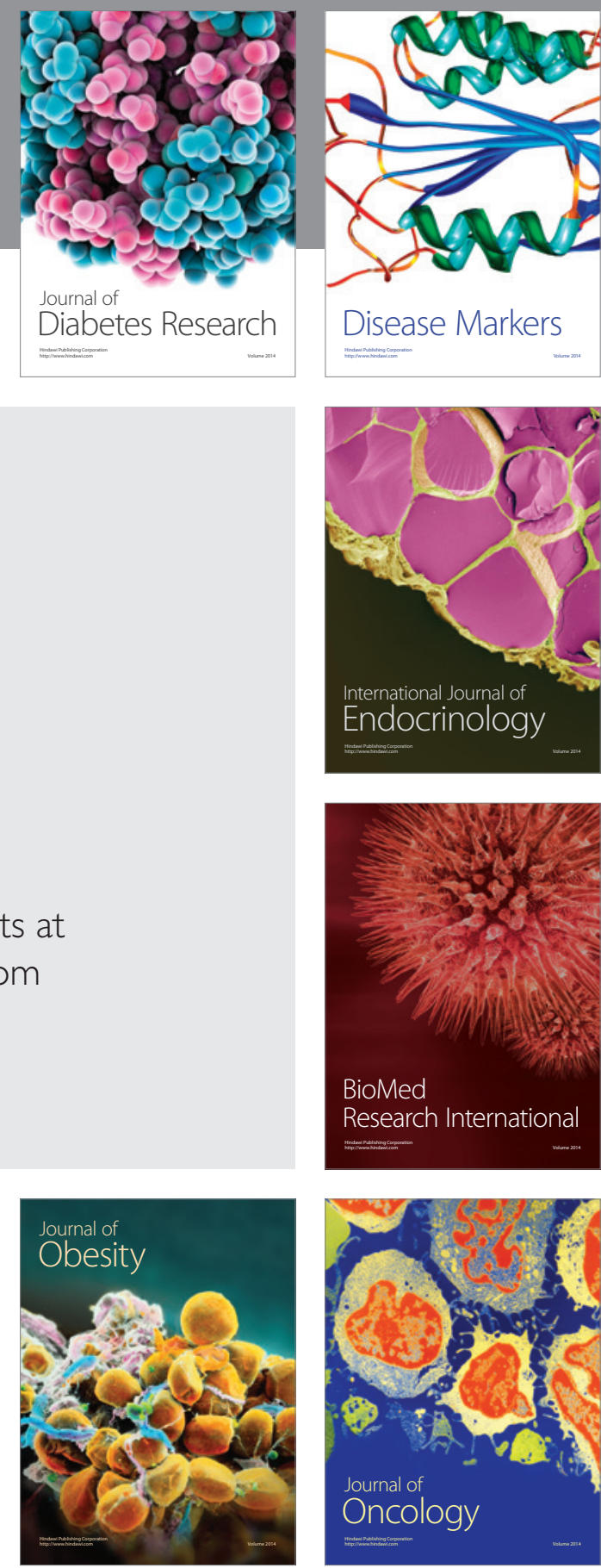

Disease Markers
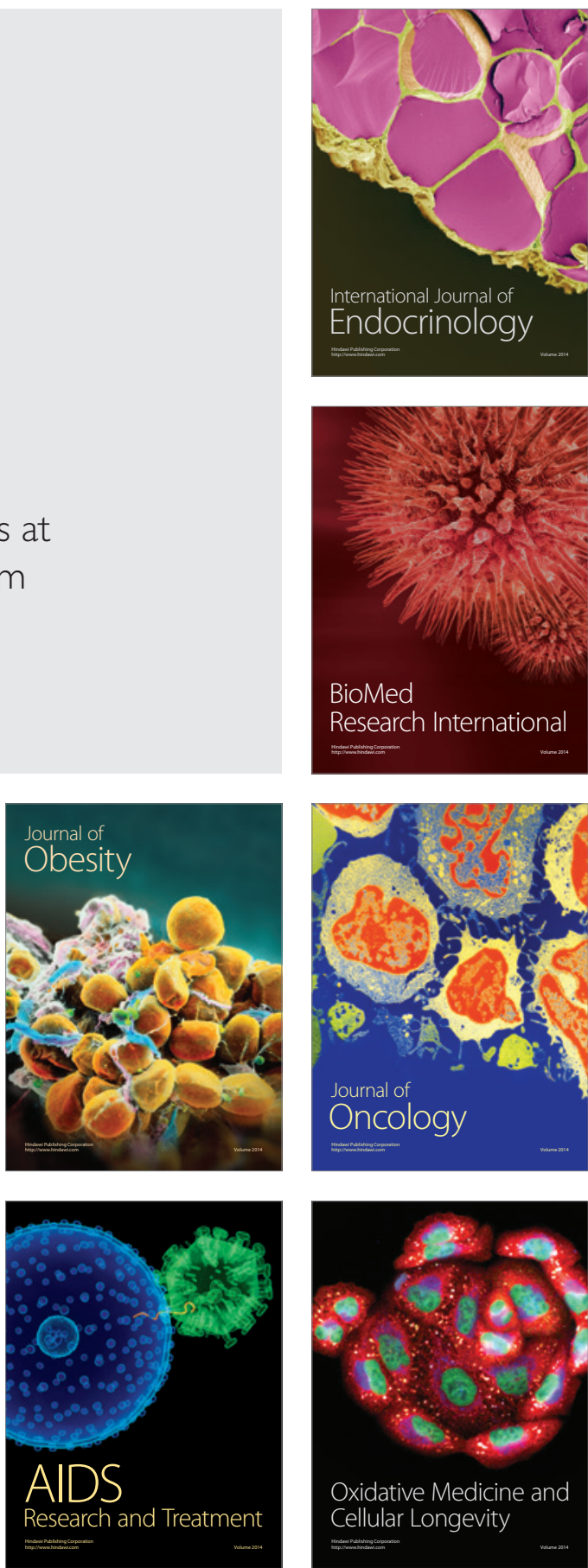